\title{
Software development for the nonprogrammer: An instructional clinical example
}

\author{
CHRIS E. STOUT \\ Forest Hospital and Foundation, Des Plaines, Illinois
}

\begin{abstract}
This paper presents an innovative way to instruct students in logical decision making in a psy. chology assessment course without their needing to know any programming language. This also yielded a tool that can aid students in making differential diagnoses of psychological as opposed to medical conditions.
\end{abstract}

The instructional use of computers in psychology continues to expand. Fifteen to 20 years ago, psychology students, professors, and researchers utilized computers primarily for data compilation and manipulation, as well as statistical procedures. They were subject to the limitations of poor availability, easy introduction of data input errors, cumbersome punch-cards, and, relative to contemporary standards, slow turn-around time for results to be generated. Certainly the impact of personal computers has markedly cured numerous problems. However, with all of the benefits of computer proliferation, computer literacy becomes difficult to define.

In the past, computer knowledge or sophistication typically implied programming skill, but today this is certainly not the case. Many psychologists and students are quite capable of using various types of software with skill and ease, yet they have no applicable knowledge of any programming language (such as FORTRAN, Pascal, TURBO C or even BASIC). It is simply not an ability needed by many psychologists who use computers. In fact, numerous individuals who would be considered computer literate have no programming experience or "literacy."

It is my opinion that such a condition is an unnecessary limitation among students and users alike. This issue was highlighted in an instructional dilemma that was met with a parsimonious and effective solution. That is, how can one teach the skill of logical, rational, unbiased, objective decision making (in this case, the making of judgments concerning psychiatric as opposed to biological diagnoses) while developing computer skills to do so,

Correspondence may be addressed to Chris E. Stout, Director, Forest Hospital and Foundation, 555 Wilson Lane, Des Plaines, IL 60016. without teaching a programming language? The solution?-Use a preexisting database program that many students are already familiar with, but instead of the typical manipulation of numeric data, use it instead to sort, define, retrieve, or list differential diagnostic data.

Differential diagnosis is an ideal conceptual framework for instruction in decision-making, because of the need to be disciplined with data collection (e.g., of symptoms), to utilize a repeatable procedure (e.g., interviews) across all subjects, and to deal with specific outcomes (e.g., possible "rule-out" diagnoses).

Various diagnostic programs have existed within mental health for many years (Hirshfeld, Spitzer, \& Miller, 1974; Overall \& Hollister, 1964; Spitzer \& Endicott, 1968; Stout, 1988b). However, many such systems were often "based on sophisticated programs that were difficult to use, were not user-friendly, or did not provide adequate descriptions"' (Stout \& Scheramic, 1989, p. 187). Stout and Scheramic have utilized preexisting software to teach psychodiagnostics. They used Aston-Tate's dBase $\mathrm{II}+$ to create files based on symptomatic and psychodiagnostic data from the Diagnostic and Statistical Manual of Mental Disorders (3rd ed.-rev.; American Psychiatric Association, 1987). The problem that their work, and that of others, had not addressed was the key issue of differentiating between diagnostic information that presents itself as psychological in nature (e.g., anxiety, depression, thought disorder, impulsivity) but that actually may have a biological etiology (e.g., endocrine disorder, carcenogenesis, toxic response).

It is difficult to incorporate all areas deemed important into a clinical psychology curriculum (or other psychology curricula for that matter). So, whenever there is the opportunity for incorporating multiple skills in a course, 
students benefit. In this example, students did not need to learn a programming language, although most were familiar with computers and database software and other nonprogramming applications. Students needed to learn, in an assessment sequence, ways in which to flag potential medical cases-that is, biological causes of what were presented as psychological problems. Numerous authors (Bishop, Sharf, \& Adkins, 1975; Hurst, Weigel, Thatcher, \& Hyman, 1969; Johnson, 1965) have noted the importance and pivotal quality of accurate diagnosis in subsequent treatment. It has been noted that "the accuracy of such differential diagnosis is paramount to proper treatment and patient care. Ignorance of a physical malady in an erroneously presumed psychiatric problem can result in permanent physical, cognitive, and emotional disability, and even death in extreme cases (not to mention litigation against the erring clinicians)" (Stout, 1988a, p. 65). Dawes, Faust, and Meehl (1989) note the superiority of actuarially based judgment over clinical judgment in terms of increased accuracy, as well as savings in both time and thus cost.

The procedure used in the present instance was to consult numerous medical texts and sources (Hall, 1980; Hall, Popkin, Devaul, Faillale, \& Stickney, 1978; Katerndah, 1982; Loschen, 1984) and to develop a "flowchart" of sorts as to what type of symptoms might be observed or queried. This flow chart was then used as a reference list to structure inquiry during an interview or assessment procedure. The noted symptoms were then input into the database; using a search condition, the user was able to obtain a listing of diagnoses associated with the symptom input. The user was then in a better position to make a referral to a medical specialist for laboratory testing and possible confirmation.

dBase III + was utilized for various reasons: (1) It is readily available and competitively priced; (2) it is popular, and many people use it; (3) with its windows and in its menu driven mode, it is user-friendly; (4) it requires no programming abilities; (5) it has good user support; and (6) it is quite powerful (Stout \& Scheramic, 1989). Hardware needs are minimal by today's standards: an IBM PC or compatible, with either two $640 \mathrm{~K}$ disk drives or a $10 \mathrm{Mb}$ hard disk drive. Graphics cards or color monitors are unnecessary.

Additionally, due to dBase III +'s flexibility, the system may be used in the reverse. For example: A clinician receives a new referral who is known to suffer from hypoparathyroidism. The clinician simply inputs the diagnosis and then uses a search condition for associated symptoms. Also incorporated into the database structure is a symptom definition field, which can assist those unfamiliar with certain medical terms (e.g., bradycardia, dyspnea, etc.). Thus, the user has a new tool with which to structure differential thinking and data collection, to develop rule-out diagnoses, to be better informed as to referral making, and to have such data rapidly provided with only a few keystrokes.

The use of a database instead of a specialized program lends itself to easier modification by nonprogrammers. As new diagnostic developments arise, the database can easily be adapted to reflect change. Additional disorders may easily be input at any time. Deficits include the fact that certain symptoms may "weigh" more, or carry more valence in relation to other symptoms leading to a rule-in diagnosis. Using a database causes all symptoms to be treated as equals. Thus, there is no current "flag" for pathogonomic symptoms in this structure. Nevertheless, this system is a modest, straightforward start, which can serve to aid in the instruction and process of differential diagnostic decision making.

Readers interested in a copy of the described program, instructions, and symptom check list are encouraged to write the author.

\section{REFERENCES}

American Psychiatric Association. (1987). Diagnostic and statistical manual of mental disorders (3rd ed.-rev.). Washington, DC. Author.

Bishop, J. B., Sharf, R. S., \& Adkins, D. M. (1975). Counselor intake judgements, client characteristics, and number of sessions at a university counseling center. Journal of Counseling Psychology, 22, 557-559.

Dawes, R. M., Faust, D., \& Meehl, P. E. (1989). Clinical versus actuarial judgment. Science, 243, 1668-1674.

Hall, R. C. (Ed.). (1980). Psychiatric presentations of medical illnesses. Somato-psychic disorders. New York: SP Medical \& Scientific Books.

Hall, R C., Popkin, M. K., Devaul, R. A., Faillale, L. A., Stickney, S. K. (1978) Physical illness presenting as psychiatric disease. Archives of General Psychiatry, 35, 1315-1320.

Hirshfeld, R., Spitzer, R. L., \& Miller, R. G. (1974). Computer diagnosis in psychiatry: A Bayes approach. Journal of Nervous \& Mental Diseases, 158, 339-407.

Hurst, J. C., Weigel, R. G , Thatcher, R. Hyman, A. J. (1969). Counselor-client diagnostic agreement and perceived outcome of counseling. Journal of Counseling Psychology, 16, 421-426.

JoHNSON, R. W. (1965). Number of interviews, diagnosis, and success of counseling. Joumal of Counseling Psychology, 12, 248-251.

Katernadah, D A. (1982). Nonpsychiatric disorders associated with depression. Journal of Family Practice, 13, 619-624

Loschen, E. L. (1984). Psychiatric syndromes with physical causes. In P. A. Keller \& L. G Ritt (Eds.), Innovations in clinical practice (pp. 41-54). Sarasota, FL: Professional Resource Exchange.

Overall, R. L., \& Hollister, L. E. (1964). Computer procedures for psychiatric classification. Journal of the American Medical Association, $18,583-585$

SPITZER, R. L., \& ENDicotT, J. (1968). DIAGNO: A computer program from psychiatric diagnoses utilizing differential diagnostic procedure. Archives of General Psychiatry, 18, 746-796.

Stout, C. E. (1988a). A clinician's guide to differential diagnosis between physical and psychiatric disorders. Medical Psychotherapy: An International Journal, 1, 65-72.

Stout, C. E. (1988b). Personal computer software for teaching differential psychodiagnostics. Behavior Research Methods, Instruments, \& Computers, 20, 106-107

Stout, C. E., \& Scheramic, M. (1989). Innovative uses of existing software in the teaching of psychodiagnostics. Behavior Research Methods, Instruments, \& Computers, 21, 187-188. 